OPEN ACCESS

Edited by:

Miguel Cacho Teixeira,

Universidade de Lisboa, Portugal

Reviewed by:

Edward M. Fox,

Commonwealth Scientific

and Industrial Research Organisation,

Ireland

Flavia Vischi Winck,

University of São Paulo, Brazil

*Correspondence:

Miguel A. De la Cruz

miguel_angel_81@live.com

Specialty section: This article was submitted to Infectious Diseases,

a section of the journal

Frontiers in Microbiology

Received: 14 December 2016

Accepted: 27 March 2017

Published: 10 April 2017

Citation:

De la Cruz MA, Ares MA

von Bargen K, Panunzi LG,

Martínez-Cruz J, Valdez-Salazar HA,

Jiménez-Galicia $C$ and Torres

(2017) Gene Expression Profiling

of Transcription Factors

of Helicobacter pylori under Different

Environmental Conditions.

Front. Microbiol. 8:615.

doi: 10.3389/fmicb.2017.00615

\section{Gene Expression Profiling of Transcription Factors of Helicobacter pylori under Different Environmental Conditions}

\author{
Miguel A. De la Cruz' ${ }^{*}$, Miguel A. Ares ${ }^{1}$, Kristine von Bargen², Leonardo G. Panunzi, \\ Jessica Martínez-Cruz ${ }^{1}$, Hilda A. Valdez-Salazar ${ }^{1}$, César Jiménez-Galicia ${ }^{4}$ and \\ Javier Torres ${ }^{1}$ \\ ' Unidad de Investigación Médica en Enfermedades Infecciosas y Parasitarias, Hospital de Pediatria, Centro Médico \\ Nacional Siglo XXI, Instituto Mexicano del Seguro Social, Mexico City, Mexico, ${ }^{2}$ Phico Therapeutics Ltd, Cambridge, UK, \\ ${ }^{3}$ CNRS UMR7280, Inserm, U1104, Centre d'Immunologie de Marseille-Luminy, Aix Marseille Université UM2, Marseille, \\ France, ${ }^{4}$ Laboratorio Clínico, Unidad Médica de Alta Especialidad, Hospital de Pediatría, Centro Médico Nacional Siglo XXI, \\ Instituto Mexicano del Seguro Social, Mexico City, Mexico
}

Helicobacter pylori is a Gram-negative bacterium that colonizes the human gastric mucosa and causes peptic ulcers and gastric carcinoma. H. pylori strain 26695 has a small genome (1.67 Mb), which codes for few known transcriptional regulators that control bacterial metabolism and virulence. We analyzed by qRT-PCR the expression of 16 transcriptional regulators in $H$. pylori 26695, including the three sigma factors under different environmental conditions. When bacteria were exposed to acidic $\mathrm{pH}$, urea, nickel, or iron, the sigma factors were differentially expressed with a particularly strong induction of fliA. The regulatory genes hrcA, hup, and $\mathrm{crd} R$ were highly induced in the presence of urea, nickel, and iron. In terms of biofilm formation fliA, flgR, hp1021, fur, nikR, and $c r d R$ were induced in sessile bacteria. Transcriptional expression levels of rpoD, flgR, $h s p R, h p 1043$, and cheY were increased in contact with AGS epithelial cells. Kanamycin, chloramphenicol, and tetracycline increased or decreased expression of regulatory genes, showing that these antibiotics affect the transcription of $\mathrm{H}$. pylori. Our data indicate that environmental cues which may be present in the human stomach modulate $H$. pylori transcription.

Keywords: H. pylori, transcription factors, environmental cues

\section{INTRODUCTION}

Helicobacter pylori is a Gram-negative bacterium, a member of the Epsilon proteobacteria that colonizes the human gastric mucosa and is responsible for causing peptic ulcers and gastric carcinoma (Marshall and Warren, 1984; Parsonnet et al., 1991; Uemura et al., 2001). H. pylori survives in the hostile environment found in the stomach, which is partially attributed to the expression of virulence factors, such as secretion systems, cytotoxins, flagella, and adhesins. Unlike other Gram-negative bacteria such as Escherichia coli or Salmonella enterica, the H. pylori genome encodes only few known transcriptional regulators, which control expression of genes involved in bacterial metabolism and pathogenicity. This limited repertoire is likely due to its life style highly adapted to one particular niche, the human gastric mucosa. H. pylori strain 26695 has a small 
genome of $1.67 \mathrm{Mb}$ (Tomb et al., 1997), and possesses three genes that code for sigma factors: $\operatorname{rpoD}\left(\sigma^{80}\right)$, rpoN $\left(\sigma^{54}\right)$, and fliA $\left(\sigma^{28}\right), \sigma^{80}$ is a homolog of Gram-negative vegetative sigma factors responsible for the transcription of housekeeping genes (Tomb et al., 1997; Beier et al., 1998), whereas $\sigma^{54}$ and $\sigma^{28}$ are two alternative sigma factors dedicated mostly to control expression of flagella components (Fujinaga et al., 2001; Josenhans et al., 2002; Niehus et al., 2004). The response regulator FlgR is also involved in regulation of flagella synthesis (Spohn and Scarlato, 1999b), whereas bacterial chemotaxis is controlled by the CheY protein (Foynes et al., 2000; Terry et al., 2005). Master regulators of response to metals such as Fur, NikR, and CrdR activate or repress genes in the presence of iron, nickel or copper, respectively (Contreras et al., 2003; Waidner et al., 2005; Pich and Merrell, 2013). Environmental cues such as acid $\mathrm{pH}$ and temperature influence expression of $\mathrm{HrcA}, \mathrm{HspR}$, and ArsR regulatory proteins (Spohn and Scarlato, 1999a; Spohn et al., 2004; Pflock et al., 2005). Although many microarrays analysis have been published (Ang et al., 2001; Merrell et al., 2003a,b; Thompson et al., 2003; Wen et al., 2003; Bury-Mone et al., 2004; Kim et al., 2004), little is known about the effects of environmental cues on the expression of $H$. pylori regulatory genes, including some poorly investigated transcriptional regulators.

In this work, we determined the expression profile of the transcriptional repertoire of $H$. pylori strain 26695 under several environmental conditions relevant for adaptation to its particular ecological niche of the human stomach, such as acidic $\mathrm{pH}$, urea, nickel, and iron. In addition, we analyzed the expression of regulatory genes in biofilm formation and in the presence of AGS gastric epithelial cells. Finally, we studied the effect of the antibiotics kanamycin, chloramphenicol, and tetracycline on the transcription of regulatory genes. Our study describes the transcriptional expression of $H$. pylori regulatory genes in response to different environmental conditions.

\section{MATERIALS AND METHODS}

\section{In silico Identification of $\boldsymbol{H}$. pylori Transcription Factors}

Selection of $H$. pylori transcription factors was performed as previously reported in the literature [(see Table 1) (Danielli

TABLE 1 | Transcription factors of Helicobacter pylori 26695

\begin{tabular}{|c|c|c|c|}
\hline Gene & Protein/Reference sequence & Functions & Reference \\
\hline rpoD (hp0088) & RpoD, $\sigma^{80 / N P \_206888.1}$ & $\begin{array}{l}\text { Vegetative sigma factor, transcription of housekeeping } \\
\text { genes }\end{array}$ & Tomb et al., 1997; Beier et al., 1998 \\
\hline rpoN (hp0714) & RpoN, $\sigma^{54} / \mathrm{NP} \_207508.1$ & $\begin{array}{l}\text { Alternative sigma factor, expression of class II flagellar } \\
\text { genes, stress and virulence }\end{array}$ & $\begin{array}{l}\text { Josenhans et al., 2002; Niehus et al., 2004; Sun } \\
\text { et al., } 2013\end{array}$ \\
\hline fliA (hp1032) & FliA, $\sigma^{28} /$ NP_207822.1 & $\begin{array}{l}\text { Alternative sigma factor, expression of class III flagellar } \\
\text { genes, stress and virulence }\end{array}$ & $\begin{array}{l}\text { Josenhans et al., 2002; Niehus et al., 2004; Baidya } \\
\text { et al., } 2015\end{array}$ \\
\hline hrcA (hp0111) & HrcA/NP_206911.1 & Involved in heat shock, stress response and motility & Spohn et al., 2004; Roncarati et al., 2007, 2014 \\
\hline $\operatorname{arsR}(h p 0166)$ & ArsR/NP_206965.1 & $\begin{array}{l}\text { Acid adaptation, acetone metabolism, oxidative stress } \\
\text { response, quorum sensing, and biofilm formation }\end{array}$ & $\begin{array}{l}\text { Pflock et al., 2005, 2006; Loh et al., 2010; Servetas } \\
\text { et al., } 2016\end{array}$ \\
\hline hp0222 & HP0222/NP_207020.1 & $\begin{array}{l}\text { Possibly involved in acid response and/or } \\
\text { bacterium-epithelial cell contact }\end{array}$ & $\begin{array}{l}\text { Ang et al., 2001; Kim et al., 2004; Popescu et al., } \\
2005\end{array}$ \\
\hline hp0564 & HP0564/NP_207359.2 & Paralog of HP0222; unknown function & Borin and Krezel, 2008 \\
\hline flgR (hp0703) & FlgR/NP_207497.1 & $\begin{array}{l}\text { RpoN-dependent master regulator of class II flagellar } \\
\text { genes }\end{array}$ & $\begin{array}{l}\text { Spohn and Scarlato, 1999b; Brahmachary et al., } \\
2004\end{array}$ \\
\hline hup (hp0835) & HU/NP_207628.1 & $\begin{array}{l}\text { Acid stress response, DNA protection from oxidative } \\
\text { stress, involved in mouse colonization }\end{array}$ & Almarza et al., 2015; Wang and Maier, 2015 \\
\hline hp1021 & HP1021/NP_207811.1 & $\begin{array}{l}\text { Chromosomal replication regulator, acetone metabolism } \\
\text { and growth }\end{array}$ & $\begin{array}{l}\text { Beier and Frank, 2000; Pflock et al., 2007a; } \\
\text { Donczew et al., } 2015\end{array}$ \\
\hline hspR (hp1025) & HspR/NP_207815.1 & Heat shock, acidic/osmotic stress response, and motility & $\begin{array}{l}\text { Spohn and Scarlato, 1999a,b; Spohn et al., } 2002 \text {, } \\
\text { 2004; Roncarati et al., } 2007\end{array}$ \\
\hline fur (hp1027) & Fur/NP_207817.1 & $\begin{array}{l}\text { Pleiotropic regulator involved in acid adaptation, metal } \\
\text { homeostasis and Mongolian gerbil/mouse colonization }\end{array}$ & $\begin{array}{l}\text { Bijlsma et al., 2002; Harris et al., 2002; van Vliet } \\
\text { et al., 2003; Bury-Mone et al., 2004; Danielli et al., } \\
\text { 2006; Gancz et al., } 2006\end{array}$ \\
\hline hsrA (hp1043) & HsrA/NP_207833.1 & $\begin{array}{l}\text { Cell viability, oxidative stress, virulence, response to } \\
\text { metronidazole }\end{array}$ & Olekhnovich et al., 2013, 2014; Vannini et al., 2016 \\
\hline cheY (hp1067) & CheY/NP_207858.1 & Chemotaxis, motility, Mongolian gerbil/mouse colonization & $\begin{array}{l}\text { Beier et al., 1997; Foynes et al., 2000; McGee } \\
\text { et al., 2005; Terry et al., } 2005\end{array}$ \\
\hline nikR (hp1338) & NikR/NP_208130.1 & $\begin{array}{l}\text { Nickel-response pleiotropic regulator, metal (copper, iron, } \\
\text { and nickel) homeostasis, acid adaptation, iron } \\
\text { uptake/storage, motility, chemotaxis, stress response, } \\
\text { and mouse colonization }\end{array}$ & $\begin{array}{l}\text { Contreras et al., 2003; Bury-Mone et al., 2004; } \\
\text { Ernst et al., 2005b; Muller et al., } 2011\end{array}$ \\
\hline $\operatorname{crdR}(h p 1365)$ & CrdR/NP_208157.1 & $\begin{array}{l}\text { Copper resistance, survival under nitrosative stress, and } \\
\text { mouse colonization }\end{array}$ & $\begin{array}{l}\text { Panthel et al., 2003; Waidner et al., 2005; Hung } \\
\text { et al., } 2015\end{array}$ \\
\hline
\end{tabular}


et al., 2010)]. Sequence data and loci annotations from 260 H. pylori genomes were retrieved from the NCBI database ${ }^{1}$ by a series of custom Perl scripts. In addition, the genomes of 57 Helicobacter non-pylori strains were included in the comparative analysis (Supplementary Table S1). Each putative transcriptional factor was queried using PSI-BLAST (Altschul et al., 1997) under the following parameters: matrix $=$ BLOSUM62, word size $=3$, PSI-BLAST threshold $=0.005$, expect threshold $=10$, and without filtering low complexity regions. Hits were carefully examined and selected according to their functional annotation.

\section{Bacterial Strains and Culture Conditions}

H. pylori 26695 was grown for 3 days on blood agar plates containing $10 \%$ defibrinated sheep blood, at $37^{\circ} \mathrm{C}$ under microaerophilic conditions. A bacterial suspension was prepared in Brucella broth (BB), and adjusted to an optical density of 0.1 at $600 \mathrm{~nm}\left(2 \times 10^{6} \mathrm{CFU} / \mathrm{ml}\right)$. H. pylori was then grown at $37^{\circ} \mathrm{C}$ for $24 \mathrm{~h}$ (logarithmic growth phase) or $48 \mathrm{~h}$ (stationary growth phase) in $\mathrm{BB}$ supplemented with $10 \%$ decomplemented fetal bovine serum $(\mathrm{BB}+\mathrm{FBS})$ under the following conditions: adjusted to $\mathrm{pH}$ 5.5 , or containing either urea $\left[5 \mathrm{mM} \mathrm{CO}\left(\mathrm{NH}_{2}\right)_{2}\right]$, nickel [250 $\mathrm{mM} \mathrm{NiCl} 2]$, or iron [150 mM $\left(\mathrm{NH}_{4}\right)_{2} \mathrm{Fe}\left(\mathrm{SO}_{4}\right)_{2} \cdot 6 \mathrm{H}_{2} \mathrm{O}$ ] as previously described (Contreras et al., 2003; Wen et al., 2003; Vannini et al., 2014; Cardenas-Mondragon et al., 2016). Fold-changes in transcription were determined by calculating the relative expression of transcription regulator genes under different environmental conditions as compared to expression in $\mathrm{BB}+$ FBS. Experiments were performed in triplicate on three different days and the results shown are the mean of the data produced.

\section{RNA Isolation and Quantitative RT-PCR}

Total RNA was extracted from bacteria grown under different culture conditions using the hot phenol method (Jahn et al., 2008) with some modifications. Briefly, after the lysate was obtained, an equal volume of phenol-saturated water was added, mixed and incubated at $65^{\circ} \mathrm{C}$ for $5 \mathrm{~min}$. The samples were chilled on ice and centrifuged at $19,000 \times g$ for $10 \mathrm{~min}$ at $4^{\circ} \mathrm{C}$. The aqueous layer was transferred to an $1.5 \mathrm{ml}$ Eppendorf tube, RNA was precipitated with cold ethanol and incubated at $-70^{\circ} \mathrm{C}$ overnight. The RNA was pelleted by centrifugation at $19,000 \times g$ for $10 \mathrm{~min}$ at $4^{\circ} \mathrm{C}$. Pellets were washed with cold $70 \%$ ethanol and centrifuged at $19,000 \times g$ for $5 \mathrm{~min}$ at $4^{\circ} \mathrm{C}$. After careful removal of the ethanol, the pellets were air dried for $15 \mathrm{~min}$ in the Centrifugal Vacuum Concentrator 5301 (Eppendorf). The pellets were resuspended in $100 \mu \mathrm{L}$ of DEPC-treated water. Purification of RNA was performed using the TURBO DNA-free kit (Ambion, Inc.). Quality of RNA was assessed using a NanoDrop (ND-1000; Thermo Scientific) and a bleach $2 \%$ agarose gel as previously described (Aranda et al., 2012). qRT-PCR was performed as previously reported (Ares et al., 2016). Specific primers were designed

${ }^{1} \mathrm{ftp}: / / \mathrm{ftp}$.ncbi.nlm.nih.gov/genomes/genbank/bacteria/
TABLE 2 | Primers for qPCR used in this study.

\begin{tabular}{|c|c|c|}
\hline Primers & Sequence & Target gene \\
\hline rpoD-F & TAT CGC TCA AGT GCC AGA AG & $r p o D$ \\
\hline rpoD-R & TGT TGG GGG CTA GAT CAA AG & \\
\hline rpoN-F & CAG CGG GTT GAA TAA TGA GG & rpoN \\
\hline rpoN-R & ACG CTT GCG CAC Tा TTC & \\
\hline fliA-F & TCG TCT AAA AGA GCG CTT GC & fliA \\
\hline fliA-R & CTT CGC ATA CCC CCA AAA AG & \\
\hline hrcA-F & TाT CTT GCG CAC TGG GTT AC & $\operatorname{hrcA}$ \\
\hline hrcA-R & GAA AGA AGC AGC GAT TGA GC & \\
\hline arsR-F & GAG CGA GTT TाT GCT CCA AC & arsR \\
\hline $\operatorname{arsR}-\mathrm{R}$ & GCC CGT CTA AAT TAG GCA AAG & \\
\hline hp0222-F & CTA GGA CGC AAA CCA AAA GC & hp0222 \\
\hline hp0222-R & CCC ACG CTT TCT TCT TCT TC & \\
\hline hp0564-F & GTC GCT GTA GAT GAG CTG AAA C & hp0564 \\
\hline hp0564-R & GGC GTT TGA CAA AAG AAT TG & \\
\hline flgR-F & CAG GCC TTA AAA GTC GCA AG & $f \lg R$ \\
\hline flgR-R & CGC TAT AAA AGG GTG CTT GG & \\
\hline hup-F & GTG GAG TTG ATC GGT TाT GG & hup \\
\hline hup-R & TTA GGC ACC CGT TTG TCT TC & \\
\hline hp1021-F & GTT GCG CAA GAT CCA ATA CC & hp1021 \\
\hline hp1021-R & AGG GCG TGT GGA TGA TAA AG & \\
\hline hspR-F & CGG GCG TGG ATA TTA TCT TG & $h s p R$ \\
\hline hspR-R & TGT TTG TGC AGA GCG TCT TG & \\
\hline fur- $\mathrm{F}$ & GAA GAA GTG GTG AGC GTT TTG & fur \\
\hline fur- $\mathrm{R}$ & СCT TाT GGC GGA TAG AAT GC & \\
\hline hsrA-F & GGA AGA AGT CCA TGC GTT TG & hsrA \\
\hline hsrA-R & CAA ACG AGC CTC AAT CCT TG & \\
\hline cheY-F & TGG AAG CTT GGG AGA AAC TG & cheY \\
\hline cheY-R & CAG AGC GCA CCT TIT TAA CG & \\
\hline nikR-F & CAT CCG CTT TTC GGT TTC & $n i k R$ \\
\hline nikR-R & CAT GTC GCG CAC TAA TTC TG & \\
\hline $\mathrm{crdR}-\mathrm{F}$ & CTT AGG CGT GGC TAA AAT GC & $\operatorname{crdR}$ \\
\hline $\mathrm{crdR}-\mathrm{R}$ & CAA ACG CCC CAA AAA CAC & \\
\hline
\end{tabular}

with the Primer3Plus software ${ }^{2}$ and are listed in Table 2. The absence of contaminating DNA was controlled by lack of amplification products after 35 qPCR cycles using RNA as template. Control reactions with no template (water) and with no reverse transcriptase were run in all experiments. 16S rRNA (HPrrnA16S) was used as a reference gene for normalization and the relative gene expression was calculated using the $2^{-\Delta \Delta C_{t}}$ method (Livak and Schmittgen, 2001). Expression of 16S rRNA remained unaffected in all conditions tested (Supplementary Figure S1).

\section{Biofilm Formation}

H. pylori was grown on blood agar medium supplemented with $10 \%$ defibrinated sheep blood at $37^{\circ} \mathrm{C}$ under microaerophilic conditions. Biofilm formation on abiotic surface (polystyrene) was analyzed using 6-well polystyrene plates, inoculated with $3 \mathrm{ml}$ of a bacterial suspension (in $\mathrm{BB}+\mathrm{FBS}$, at a final concentration of $\mathrm{OD}_{600 \mathrm{~nm}}=0.1$ ) in each well. The plates

\footnotetext{
${ }^{2}$ http://www.bioinformatics.nl/cgi-bin/primer3plus/primer3plus.cgi/
} 
were incubated during 3 days at $37^{\circ} \mathrm{C}$ under microaerophilic conditions as previously reported (Cardenas-Mondragon et al., 2016). Supernatant (planktonic) and adhered (sessile) bacteria were recovered for RNA extraction. Fold-change in gene transcription was determined by calculating the relative expression of transcription regulator genes within biofilms (sessile bacteria) as compared to planktonic bacteria. Quantifications were performed in triplicate on three different days and the results shown are the mean of the three experiments.

\section{Infection of AGS Cells}

AGS gastric epithelial cells were grown to about $75 \%$ confluence in RPMI-1640 medium containing 10\% FBS, and washed thrice with PBS before adding fresh RPMI media with 10\% FBS. H. pylori 26695 was grown in BB + FBS for $24 \mathrm{~h}$, suspended in RPMI, and added to the AGS cell culture at a multiplicity of infection (MOI) of 100 (bacteria/cell). Infected cells were incubated at $37^{\circ} \mathrm{C}$ under microaerophilic conditions for 0 or $6 \mathrm{~h}$, and bacteria were recovered. At the end of the incubation period, the $H$. pylori-infected AGS cells were washed thrice with PBS and lysed with $0.1 \%$ Triton X-100 for $10 \mathrm{~min}$. Large debris and nuclei were removed by centrifugation for $5 \mathrm{~min}$ at $200 \times g$ and adhered bacteria were pelleted at 20,000 $g$ for $10 \mathrm{~min}$. RNA was extracted from adhered bacteria to determine gene expression. Fold-change in gene transcription was determined by calculating the relative expression of the transcription factors genes with respect to bacteria at time 0 of infection. Fold-change in gene transcription of $H$. pylori grown in RPMI-1640 + FBS (for 0 or $6 \mathrm{~h}$ ) was calculated as control of expression. Assays were performed in triplicate on three different days and the results shown are the mean of the three experiments.

\section{Transcription in the Presence of Antibiotics}

H. pylori was grown in $\mathrm{BB}+\mathrm{FBS}$ at $37^{\circ} \mathrm{C}$ for $48 \mathrm{~h}$ (stationary phase), with gentle shaking under microaerophilic conditions. The antibiotics kanamycin $(\mathrm{Km}, 50 \mu \mathrm{g} / \mathrm{mL})$, chloramphenicol (Cm, $30 \mu \mathrm{g} / \mathrm{mL}$ ) or tetracycline (Tc, $10 \mu \mathrm{g} / \mathrm{mL}$ ) were added and the cultures were incubated for $1 \mathrm{~h}$ as previously described (Christensen-Dalsgaard et al., 2010; Cardenas-Mondragon et al., 2016). Antibiotics were used at the minimal inhibitory concentrations that have been reported for E. coli and S. enterica (Christensen-Dalsgaard et al., 2010; Maisonneuve et al., 2011; Silva-Herzog et al., 2015; Li et al., 2016). Fold-change in gene transcription was determined by calculating the relative expression of the transcription regulators genes in the presence of each antibiotic as compared to bacteria growing without antibiotics for $1 \mathrm{~h}$. Experiments were performed in triplicate on three different days and the results shown are the mean of the three experiments.

\section{Heatmap Construction}

To show the fold-changes in gene expression, we selected the "heatmap.2" function of the R software, using the "gplots" package. The rows (culturing conditions) were hierarchically clustered ("hclust" function, "ward.D" method) according to the absolute fold-changes in gene expression.

In order to illustrate the presence/absence of transcription factors in all Helicobacter genomes, an amino acid sequences content matrix ("heatmap" function) was built using the $\mathrm{R}$ software $^{3}$ (v3.2.4). $260 \mathrm{H}$. pylori and $57 \mathrm{H}$. non-pylori genomes were retrieved from the NCBI database $e^{4}$ by a series of custom Perl scripts. These paired loci were hierarchically clustered ("hclust" function, "ward.D" method) according to their loci-content using a sidelong dendrogram.

\section{Statistical Analysis}

For statistical differences, one-way ANOVA followed by the Tukey's comparison test was performed using Prism5.0 (GraphPad Software Inc., San Diego, CA, USA). $p \leq 0.05$ was considered statistically significant.

\section{RESULTS}

\section{Environmental Cues that Trigger the Expression of Transcription Factor Genes}

$H$. pylori adaptation to the gastric mucosa conditions is mediated by a limited number of regulatory genes. An analysis of the reports of $26695 \mathrm{H}$. pylori strain identified 16 genes that code for transcriptional regulators, including three sigma factors (Table 1). We performed qRT-PCR on RNA extracted from bacteria grown during both exponential $(24 \mathrm{~h})$ and stationary phase $(48 \mathrm{~h})$ and the expression of all regulatory genes was calculated during both growth phases. Expression of most genes was higher during stationary phase than in exponential phase, except for $r p o D$ and $h p 0564$ (Figure 1A). Therefore, we determined the expression of all transcription regulators during stationary phase in media with acid $\mathrm{pH}$ or in the presence of urea, nickel, or iron. None of these environmental variations promoted or inhibited growth of H. pylori (Figure 1B). Interestingly, the conditions tested resulted mostly in increased expression of transcription regulators (Figures 1C-F, 4). Regarding sigma factors, fliA expression increased with all treatments, with the highest induction levels observed in response to nickel. The same was true for $r p o D$ with exception of treatment with iron, which resulted in down regulation of the gene (Figure 1F); whereas rpoN expression significantly increased only after exposure to urea or nickel (Figures 1D,E). Concerning the other transcriptional regulators, acidic $\mathrm{pH}$ resulted in down regulation of $\operatorname{ars} R$, $h p 0564$, and $f l g R$ and a moderate increase of hup, cheY, or $c r d R$, whereas the remaining genes were unaffected (Figure 1C). Exposure of bacteria to urea and nickel ions resulted in more pronounced transcriptional changes (Figures 1D,E). However, whereas expression of most transcription factors increased considerably, hp0564 and fur showed only subtle

\footnotetext{
${ }^{3}$ http://www.R-project.org/

${ }^{4} \mathrm{ftp} / / / \mathrm{ftp} . n c b i . n l m . n i h . g o v / g e n o m e s / g e n b a n k / b a c t e r i a /$
} 


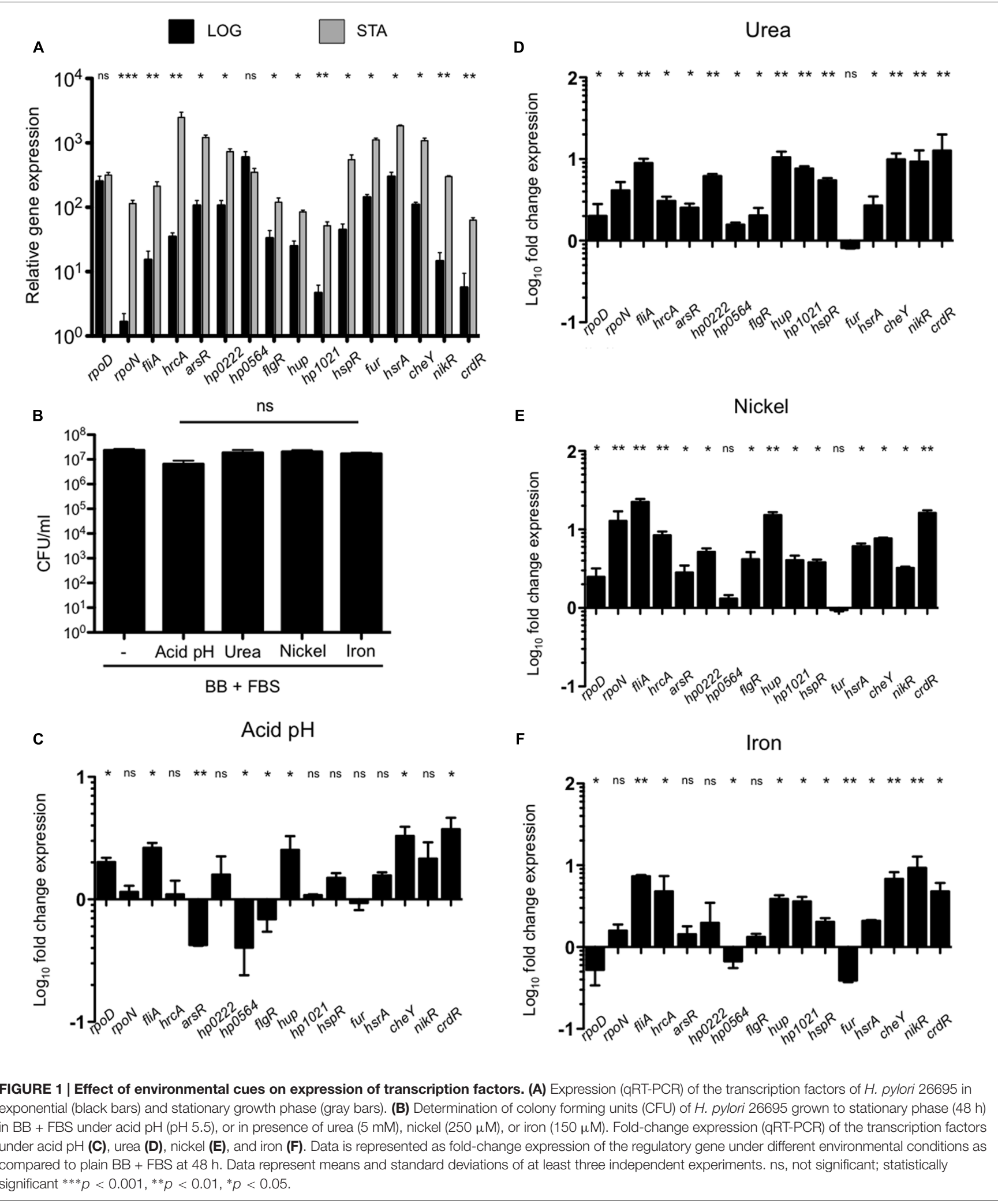

changes in response to urea and nickel. hp0564, fur, and $r p o D$ were the only genes tested to be down regulated in response to iron, whereas expression of the other transcription regulators increased ( $h r c A$, hup, hp1021, hsrA, cheY, nikR, and $c r d R)$, or did not change (arsR, hp0222, flgR, and $h s p R)$ (Figure 1F). 


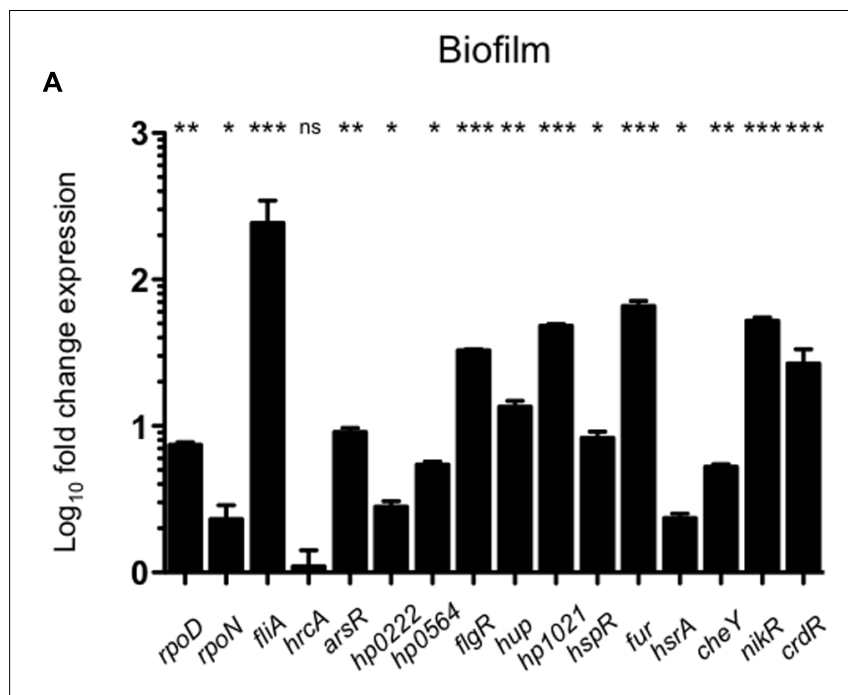

B

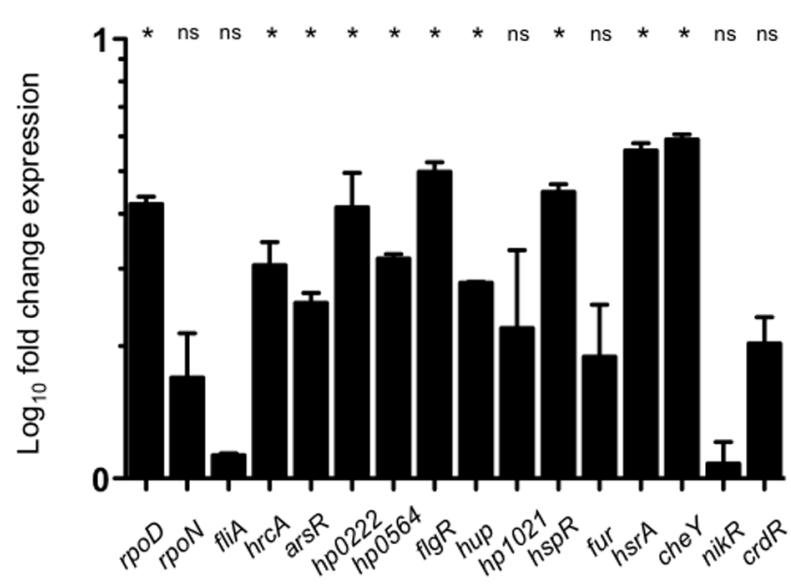

FIGURE 2 | Expression of transcription regulators during biofilm formation or in response to interaction with AGS cells. Expression levels of the transcription regulators during bacterial biofilm formation (A) or H. pylori interaction with AGS cells (B) were determined by GRT-PCR. Data are expressed as fold-change expression levels and represent means and standard deviations of at least three independent experiments. ns, not significant; statistically significant ${ }^{* * *} p<0.001,{ }^{* *} p<0.01,{ }^{*} p<0.05$.

\section{The Effect of Biofilm Formation and Interaction with Gastric Epithelial Cells on Expression of $\boldsymbol{H}$. pylori Transcription Factors}

During infection, $H$. pylori closely interacts with the cells of the gastric mucosa, which may result in bacterial biofilm formation in later stages of infection (Carron et al., 2006). To study the effect of bacterial interaction with cells of the gastric mucosa or the growth in biofilms on the expression of transcription regulators, bacteria were grown either stationary on polystyrene surfaces or brought into contact with AGS cells, and their transcription profiles were analyzed. As control for the interaction with
AGS cells, $H$. pylori was grown in RPMI-1640 medium for the same amount of time, which did not result in any changes in gene transcription. Expression of rpoN did not change during growth in biofilm or upon attachment to AGS cells, whereas rpoD expression increased under both conditions (Figure 2A). However, the most striking effect among the three sigma factors was a dramatic increase of $f l i A$ expression in response to biofilm formation (Figure 2). Only few of the other regulatory genes remained unaffected by the interaction with abiotic surfaces ( $h r c A)$, or epithelial cells ( $h p 1021, f u r, n i k R$, and $c r d R)$. All other transcriptional regulators were up regulated upon contact with AGS cells, and to a greater extent during biofilm formation (Figures 2, 4).

\section{Antibiotic Exposure Decreases Expression of Most $\boldsymbol{H}$. pylori Transcription Regulators}

Our group recently reported that antibiotics affect the expression of virulence factors in H. pylori (Cardenas-Mondragon et al., 2016). Whereas the environmental conditions tested here mostly up regulated expression of the transcription regulators analyzed, exposure to different antibiotics resulted predominantly in gene repression (Figures 3,4). This was likely not due to compromised cell growth, since the antibiotic concentrations used here did not affect the viability of the bacteria (Supplementary Figure S2). Among the three sigma factors, $r p o D$ expression was not affected by exposure to kanamycin or tetracycline and increased in response to chloramphenicol (Figure 3), whereas expression of rpoN and fliA was down regulated or not affected after exposure to all three antibiotics tested (Figure 3). Expression levels of the other transcription regulators were mostly repressed in response to antibiotic treatment, particularly upon exposure to kanamycin or chloramphenicol (Figures 3A,B). Only $h r c A$ and hup mRNA levels were slightly increased in the presence of kanamycin, whereas those of $h p 1021$ were not affected (Figure 3A). While negatively regulating expression of most transcription factors, chloramphenicol led to a mild increase of hup and hp1021 levels, and did not affect expression of fur (Figure 3B). In contrast, tetracycline had stimulating effects on the expression of several transcription factors, including $h p 0166, h p 0222$ hp0564, hup, and $h p 1021$ (Figure 3C). Transcription of $f l g R$, nikR, and $c r d R$ decreased upon tetracycline treatment, whereas transcription levels of $h r c A, h s p R$, and $c h e Y$ were not affected (Figure 3C).

\section{Transcriptional Regulator Genes Are Highly Conserved in $\boldsymbol{H}$. pylori Strains}

We performed a Blast search in genomes deposited in GenBank ${ }^{5}$ using the amino acids sequences of the 16 transcriptional regulators identified in $H$. pylori 26695 . The transcription factors were highly prevalent and well conserved among different H. pylori isolates (Figure 5). We studied the occurrence of these genes in other Helicobacter species, and found that their presence changed from one species to another. Two species that are phylogenetically closely related to $H$. pylori, $H$. acinonychis

${ }^{5}$ http://www.ncbi.nlm.nih.gov/genbank/ 

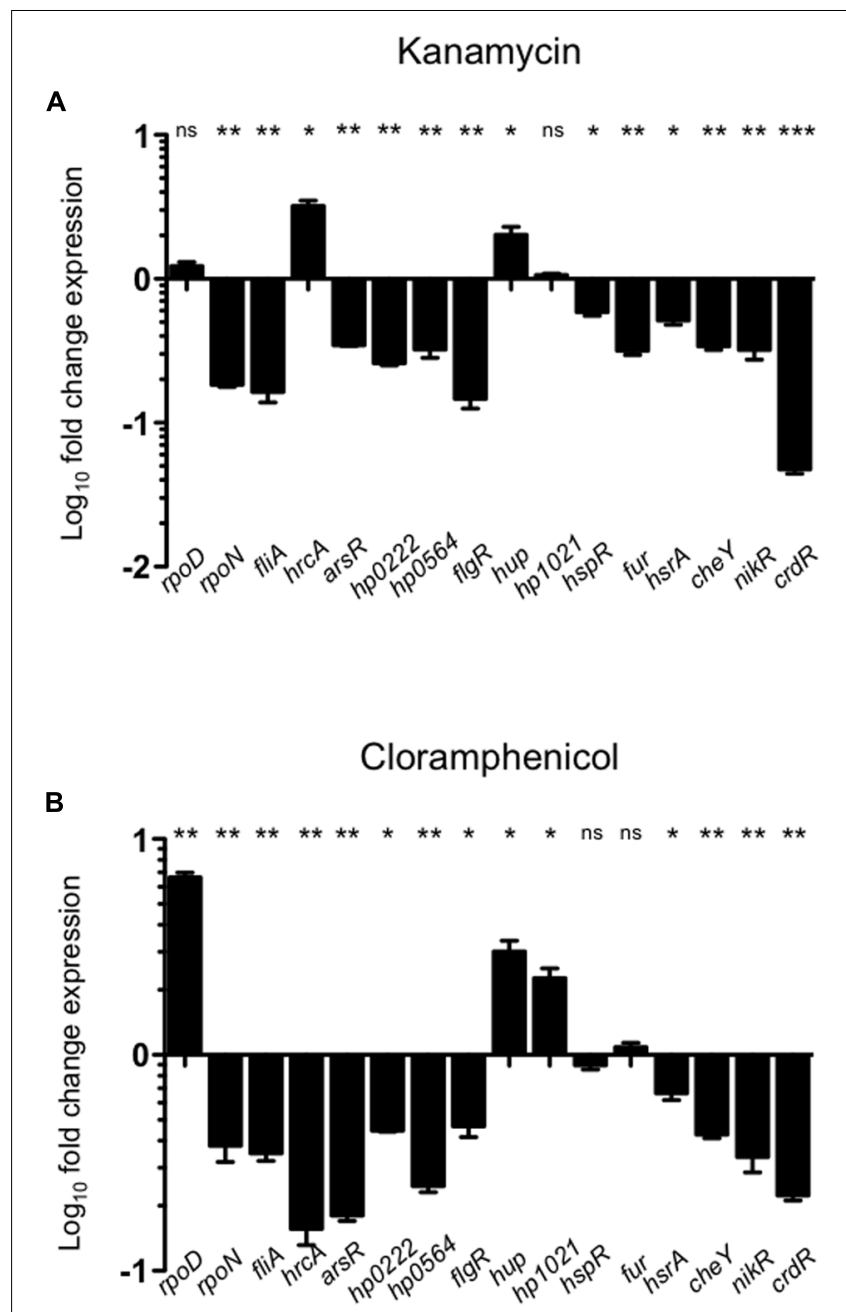

c

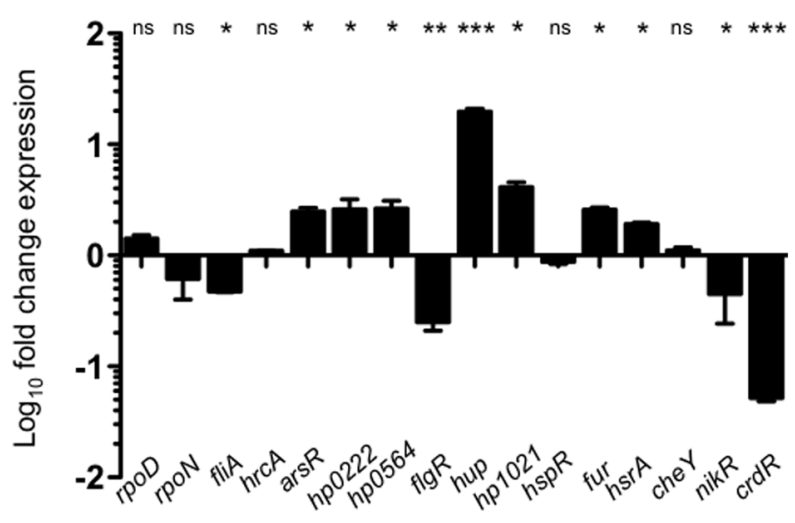

FIGURE 3 | Effect of antibiotics on expression of transcription factors. Expression levels of transcription factors after treatment of bacteria with different antibiotics [Kanamycin (A), Chloramphenicol (B), and Tetracycline (C)] for $1 \mathrm{~h}$ were determined by qRT-PCR and compared to those in untreated bacteria. Data are expressed as fold-change expression and represent the means and standard deviations of at least three independent experiments. ns, not significant; statistically significant ${ }^{* * *} p<0.001,{ }^{* *} p<0.01,{ }^{*} p<0.05$. (isolated from big cats), and $H$. cetorum (isolated from marine mammals), encoded all 16 transcriptional regulators with high identities to those of $H$. pylori strains, and clustered closer to the $H$. pylori strains (Figure 5). Interestingly, transcription regulators such as $h p 0222$ and $h p 0564$ presented low prevalence in most of the $H$. non-pylori strains, showing that both proteins are highly conserved in $H$. pylori, $H$. acinonychis, and H. cetorum.

\section{DISCUSSION}

H. pylori is a highly specialized bacterium that is exclusively found in the human gastric mucosa. In this work, we describe the expression of $H$. pylori transcriptional regulatory genes under different environmental conditions. Most transcription factors were highly expressed when $H$. pylori reached the early stationary phase. At this growth phase, H. pylori is exposed to specific stress signals such as $\mathrm{pH}$ changes, starvation, reactive oxygen species that would activate its transcriptional repertoire, suggesting that the stationary phase may mimic the conditions found by the bacteria in the host. Acid $\mathrm{pH}$, the presence of urea, nickel, or iron are environmental cues required for optimal adaptation of $H$. pylori to its natural niche. Whereas all of the above conditions boosted fliA expression, rpoD showed only a mild increase in transcription after bacterial exposure to acid $\mathrm{pH}$, urea, and nickel, and a decrease in response to iron. The expression of rpoN significantly increased upon treatment of bacteria with urea or nickel; RpoN was initially described as regulator of flagellar genes, but recent studies show that it also controls several bacterial regulatory processes involved in energy metabolism, biosynthesis, protein fate, oxidative stress, and virulence (Sun et al., 2013). fliA was strongly expressed even under environmental conditions that are not common inducers of flagella synthesis, but are known to affect other bacterial components or pathways. In fact, FliA regulates expression of outer membrane proteins, lipopolysaccharide synthesis, DNA restriction, and CagA (Josenhans et al., 2002; Baidya et al., 2015), a protein involved in virulence and associated with the development of gastric carcinoma (Ohnishi et al., 2008). Our data support the notion that FliA regulates different bacterial functions other than the flagellum.

H. pylori is exposed to changes in $\mathrm{pH}$ while passing from the stomach lumen through the mucus layer to interact with epithelial cells, and this $\mathrm{pH}$ gradient is used by the bacteria for spatial orientation (Schreiber et al., 2004). Accordingly, changes in $\mathrm{pH}$ strongly affect expression of transcriptional regulators that control genes involved in colonization and persistence in the human host. Our data show that an acidic $\mathrm{pH}$ repressed arsR, hp0564, and flgR, while stimulating hup, cheY, and $c r d R$. The hup gene codes for the HU nucleoid protein, which has a regulatory role in the response to acid stress in $H$. pylori. Thus, hup mutants are less viable than wild type bacteria at $\mathrm{pH}$ 5.5 and during stomach colonization due to down regulation of both urease (ureA) and arginine decarboxylase (speA) in the absence of HU nucleoid protein (Wang et al., 2012; Almarza et al., 2015). CheY and CrdR response regulators are also crucial for a successful colonization of the animal stomach (Foynes 


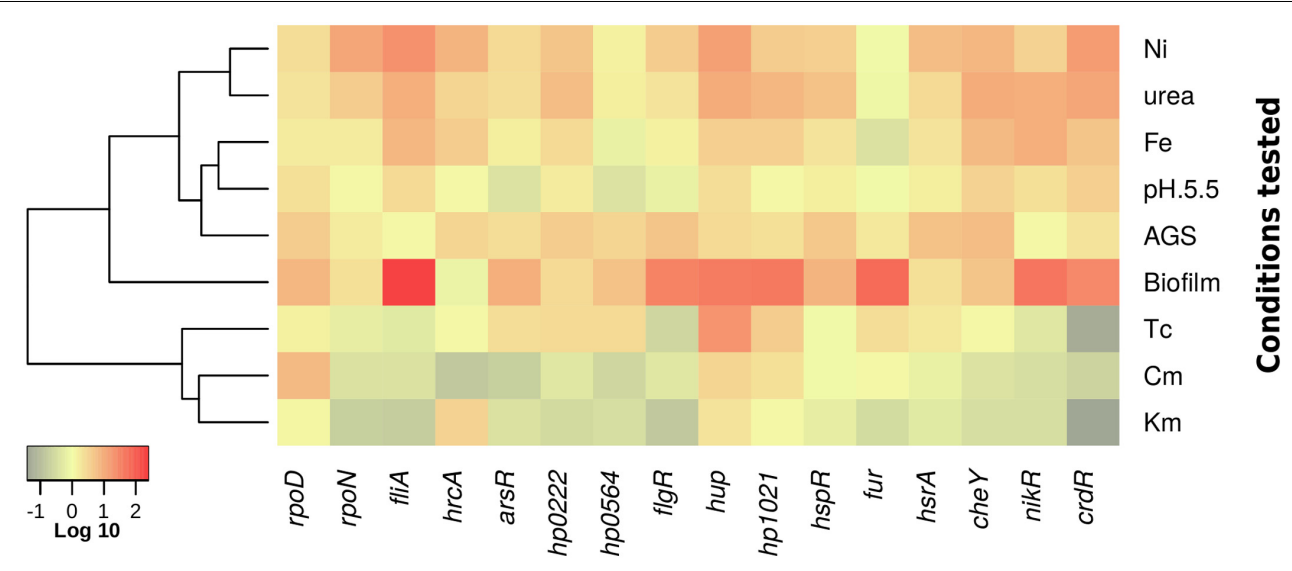

Transcription factors

FIGURE 4 | Summary of effects of different environmental stimuli on expression of $\boldsymbol{H}$. pylori transcription factors. Heatmap of gene expression levels at diverse culturing conditions. Relative gene expression values are expressed as fold-changes in a Log 10 scale. The color-coding scale denotes up regulation in red and down regulation in green.

et al., 2000; Panthel et al., 2003; McGee et al., 2005; Terry et al., 2005). CheY expression is essential for the chemotactic motility required to reach and colonize the gastric epithelia, and is likely to be triggered in the acidic milieu of the stomach lumen. In contrast, CrdR has not been shown to be involved in the regulation of gene expression in response to acidic $\mathrm{pH}$ (Pflock et al., 2007b), although copper can be present in the acidic environment of the human stomach, and regulation of its uptake is important for keeping the balance between supplying copper as respiration co-factor, and avoiding copper-induced toxicity (Haley and Gaddy, 2015). Interestingly, the master regulator of the acid response ars $\mathrm{R}$ was repressed in acidic $\mathrm{pH}$, which confirms reports that ArsR may also act as transcriptional auto-repressor under an acidic pH (Dietz et al., 2002).

Urea, nickel, and iron are crucial for H. pylori pathogenesis and they control regulatory networks responding to their presence. We found that expression of most of the transcription regulators tested increased when bacteria were exposed to urea, nickel, or iron. Nickel serves as essential co-factor for the urease enzyme, which enables $H$. pylori survival at acidic $\mathrm{pH}$ (Khan et al., 2009). The up regulation of nikR expression that we observed contrasted with the auto-negative regulation reported for the nikR promoter (Delany et al., 2002; Contreras et al., 2003). The conditions of growth (stationary phase) and nickel concentrations $(250 \mu \mathrm{M})$ that we tested resulted in increased nikR expression. However, nikR expression showed slight variations in response to low $(1 \mu \mathrm{M})$ and high $(100 \mu \mathrm{M})$ concentrations of nickel (Davis et al., 2006), suggesting that nickel may modulate nikR transcription in a concentration-dependent manner. Interestingly, $r p o D$ and fur were down regulated in the presence of iron. While iron-mediated fur repression can be explained by the negative auto-regulation of this transcription factor upon iron-binding (Delany et al., 2002), the decrease in $r p o D$ levels is hard to explain. Whilst the evaluation of each environmental condition provides relevant information about
H. pylori physiology, the combination of these stimuli could better mimic the in vivo response of the bacteria in the infection context.

One of the strategies employed by $H$. pylori to persist and colonize the stomach is biofilm formation. Analysis of bacteria grown in biofilm revealed an interesting expression pattern of the three sigma factors: whereas rpoN was not affected, expression of $r p o D$ and $f l i A$ increased during biofilm formation. FliA has been found to control the $\operatorname{lp} x C$ gene, which is involved in the early steps of lipid A synthesis in $H$. pylori (Josenhans et al., 2002). The marked increase of fliA expression that we found in sessile, aggregated bacteria is in agreement with reports about the effect of lipid A architecture on biofilm formation (Gaddy et al., 2015). In addition, with the exception of $h r c A$, expression of all transcription factor genes studied increased during biofilm formation, and the relative increase of several of them was the highest increase observed across all the conditions tested. This remarkably activated state of the regulatory transcriptome highlights the importance of forming sessile microbial communities in $H$. pylori ecology.

Similar to the response during biofilm formation, the presence of gastric epithelial cells significantly increased expression levels of several transcription factors, except for fur, $n i k R$, and $c r d R$. Expression of these three master regulators of virulence remained unaffected in our AGS cell model, which correlates with the previously reported lack of activation or repression of these regulators after the interaction with gastric epithelial cells (Kim et al., 2004).

It has been hypothesized that the reduced number of transcriptional regulators in the $H$. pylori genome has been compensated by gain of functions in the remaining transcription factors, as compared to their functions by homologs found in other species (Ernst et al., 2005a). For instance, the H. pylori Fur protein was not only found to be involved in iron homeostasis, but it also participated in several other additional pathways 
including those of oxidative stress resistance (Harris et al., 2002) and acid regulation (Bijlsma et al., 2002; van Vliet et al., 2004), and has been found essential for colonization of the gastric mucosa (Bury-Mone et al., 2004). Moreover, unlike Fur homologs in other species, $H$. pylori Fur has been found to mediate gene regulation even in its iron-free (apo) form (Bereswill et al., 2000; Delany et al., 2001; Carpenter et al., 2013). Interestingly, whereas most conditions tested here showed only moderate effects on Fur expression, biofilm formation resulted in a marked up regulation of the gene, suggesting functions beyond regulation of iron metabolism.

The presence of antibiotics can alter the expression of genes related to the bacterial stress and virulence on a transcriptional level. Interestingly, most regulatory genes were repressed in response to antibiotic treatment. $r p o N, f l i A, f l g R$, and $c r d R$ genes presented a negative regulation profile in the presence of kanamycin, chloramphenicol, and tetracycline. In contrast, expression levels of $r p o D$ and hup were highly stimulated under chloramphenicol or tetracycline treatment. These last antibiotics inhibit bacterial translation, differentially affecting the $50 \mathrm{~S}$ and $30 \mathrm{~S}$ ribosomal subunits, respectively. The molecular mechanisms responsible for the regulation in expression of transcriptional regulators in the presence of antibiotics have been poorly studied. About this, 16S rRNA expression was affected in the presence of kanamycin and chloramphenicol, showing that this gene was not completely stable and that antibiotic treatment may have affected the expression of this reference gene under these conditions. For a better analysis in presence of these antibiotics, it is necessary the selection and validation of other reference genes for qRT-PCR normalization as was recently reported (Martins et al., 2017).

During analysis of Helicobacter sequences we found that the transcriptional regulators were highly identical among $H$. pylori species. Interestingly, $H$. acynonichis and $H$. cetorum grouped together with $H$. pylori, corroborating the close phylogenetic relation between these species. The transcriptional regulators HP0222 and HP0564 appear to be conserved in H. pylori and its closely related species, while they were absent in most of the remaining Helicobacter species. Since H. pylori, H. acynonichis, and $H$. cetorum are all found within mammalian stomachs, these two regulators may confer an adaptive advantage in this particular ecological niche. In line with these findings, expression levels of both, $h p 0564$ and $h p 0222$ increased in contact with AGS gastric epithelial cells, corroborating a report by Kim et al. (2004) on $h p 0222$. However, we did not observe enhanced $h p 0222$ expression under acidic $\mathrm{pH}$, contrasting with the report by Ang et al. (2001).

Recently, we reported the transcriptional profiling of type II toxin-antitoxin genes under different environmental conditions (Cardenas-Mondragon et al., 2016). The type II antitoxins function as transcriptional repressors of their own expressions (Yamaguchi and Inouye, 2011) and also regulate the expression of other genes related with cellular functions such as biofilm formation, persistence, and the general stress response (Wang and Wood, 2011; Hu et al., 2012). Our findings here expand the transcriptional repertoire of $H$. pylori to respond to the different stresses found in the stomach niche.

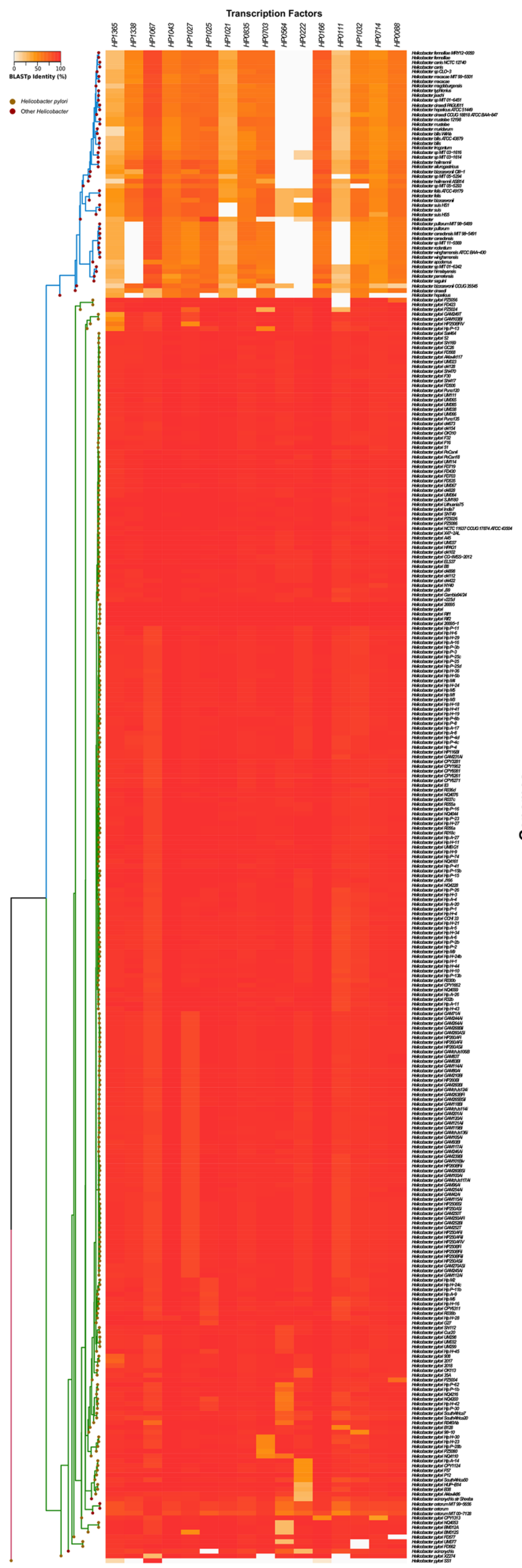

FIGURE 5 | Prevalence of transcription regulators in the Helicobacter genus. Amino acid sequences of Helicobacter transcription factors were analyzed. Heatmaps and hierarchical clustering of selected amino acid sequences for transcription factors for both Helicobacter and Helicobacter non-pylori showing the identity of transcription regulators were created using the R (version 3.2.4) hclust function with the "ward.D" method. 
In summary, our data show that the repertoire of transcriptional regulators of $H$. pylori possesses a functional plasticity needed to respond to different environmental cues and to integrate them for the survival and persistence of this bacterium in the stomach niche.

\section{AUTHOR CONTRIBUTIONS}

Conceived and designed the experiments: MDC. Performed the experiments: MDC, KvB, MA, LP, JM-C, HV-S, and CJ-G. Analyzed the data: MDC, KvB, and MA. Wrote the paper: MDC, $\mathrm{KvB}$, and JT.

\section{FUNDING}

This study was supported by grant FIS/IMSS/PROT/G14/1332 (to MDC) from the Fondo de Investigación en Salud (FIS)-IMSS, México

\section{REFERENCES}

Almarza, O., Nunez, D., and Toledo, H. (2015). The DNA-binding protein HU has a regulatory role in the acid stress response mechanism in Helicobacter pylori. Helicobacter 20, 29-40. doi: 10.1111/hel.12171

Altschul, S. F., Madden, T. L., Schaffer, A. A., Zhang, J., Zhang, Z., Miller, W., et al. (1997). Gapped BLAST and PSI-BLAST: a new generation of protein database search programs. Nucleic Acids Res. 25, 3389-3402. doi: 10.1093/nar/25.17.3389

Ang, S., Lee, C. Z., Peck, K., Sindici, M., Matrubutham, U., Gleeson, M. A., et al. (2001). Acid-induced gene expression in Helicobacter pylori: study in genomic scale by microarray. Infect. Immun. 69, 1679-1686. doi: 10.1128/iai.69.3.16791686.2001

Aranda, P. S., Lajoie, D. M., and Jorcyk, C. L. (2012). Bleach gel: a simple agarose gel for analyzing RNA quality. Electrophoresis 33, 366-369. doi: 10.1002/elps. 201100335

Ares, M. A., Fernandez-Vazquez, J. L., Rosales-Reyes, R., Jarillo-Quijada, M. D., Von Bargen, K., Torres, J., et al. (2016). H-NS nucleoid protein controls virulence features of Klebsiella pneumoniae by regulating the expression of type 3 pili and the capsule polysaccharide. Front. Cell Infect. Microbiol. 6:13. doi: $10.3389 /$ fcimb. 2016.00013

Baidya, A. K., Bhattacharya, S., and Chowdhury, R. (2015). Role of the flagellar hook-length control protein FliK and sigma28 in cagA expression in gastric celladhered Helicobacter pylori. J. Infect. Dis. 211, 1779-1789. doi: 10.1093/infdis/ jiu 808

Beier, D., and Frank, R. (2000). Molecular characterization of two-component systems of Helicobacter pylori. J. Bacteriol. 182, 2068-2076. doi: 10.1128/jb.182. 8.2068-2076.2000

Beier, D., Spohn, G., Rappuoli, R., and Scarlato, V. (1997). Identification and characterization of an operon of Helicobacter pylori that is involved in motility and stress adaptation. J. Bacteriol. 179, 4676-4683. doi: 10.1128/jb.179.15.46764683.1997

Beier, D., Spohn, G., Rappuoli, R., and Scarlato, V. (1998). Functional analysis of the Helicobacter pylori principal sigma subunit of RNA polymerase reveals that the spacer region is important for efficient transcription. Mol. Microbiol. 30, 121-134. doi: 10.1046/j.1365-2958.1998.01043.x

Bereswill, S., Greiner, S., Van Vliet, A. H., Waidner, B., Fassbinder, F., Schiltz, E., et al. (2000). Regulation of ferritin-mediated cytoplasmic iron storage by the ferric uptake regulator homolog (Fur) of Helicobacter pylori. J. Bacteriol. 182, 5948-5953. doi: 10.1128/jb.182.21.5948-5953.2000

Bijlsma, J. J., Waidner, B., Vliet, A. H., Hughes, N. J., Hag, S., Bereswill, S., et al. (2002). The Helicobacter pylori homologue of the ferric uptake regulator is

\section{ACKNOWLEDGMENT}

We thank Diana Márquez-Delfín for technical assistance.

\section{SUPPLEMENTARY MATERIAL}

The Supplementary Material for this article can be found online at: http://journal.frontiersin.org/article/10.3389/fmicb. 2017.00615/full\#supplementary-material

FIGURE S1 | Expression of reference gene (HPrrnA16S) under different environmental conditions. Panels show the expression of reference gene during stationary phase in $\mathrm{BB}+\mathrm{FBS}$ with changes in $\mathrm{pH}$ and concentrations of urea, nickel, and iron (A), or in presence of antibiotics (B) or in contact on abiotic and biotic surfaces (C). (-) Indicates the BB + FBS plain (neutral pH with no addition of components). Quantification of expression is showed as copies of

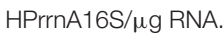

FIGURE S2 | Effect of antibiotics on $\boldsymbol{H}$. pylori growth. Determination of colony forming units (CFU) of $H$. pylori 26695 grown during $1 \mathrm{~h}$ in presence of antibiotics (Km, Kanamycin; Chloramphenicol, Cm; Tetracycline, Tc).

involved in acid resistance. Infect. Immun. 70, 606-611. doi: 10.1128/iai.70.2. 606-611.2002

Borin, B. N., and Krezel, A. M. (2008). Structure of HP0564 from Helicobacter pylori identifies it as a new transcriptional regulator. Proteins 73, 265-268. doi: 10.1002/prot.22159

Brahmachary, P., Dashti, M. G., Olson, J. W., and Hoover, T. R. (2004). Helicobacter pylori FlgR is an enhancer-independent activator of sigma54-RNA polymerase holoenzyme. J. Bacteriol. 186, 4535-4542. doi: 10.1128/JB.186.14.4535-4542. 2004

Bury-Mone, S., Thiberge, J. M., Contreras, M., Maitournam, A., Labigne, A., and De Reuse, H. (2004). Responsiveness to acidity via metal ion regulators mediates virulence in the gastric pathogen Helicobacter pylori. Mol. Microbiol. 53, 623-638. doi: 10.1111/j.1365-2958.2004.04137.x

Cardenas-Mondragon, M. G., Ares, M. A., Panunzi, L. G., Pacheco, S., CamorlingaPonce, M., Giron, J. A., et al. (2016). Transcriptional profiling of type II toxin-antitoxin genes of Helicobacter pylori under different environmental conditions: identification of HP0967-HP0968 system. Front. Microbiol. 7:1872. doi: 10.3389/fmicb.2016.01872

Carpenter, B. M., Gilbreath, J. J., Pich, O. Q., Mckelvey, A. M., Maynard, E. L., Li, Z. Z., et al. (2013). Identification and characterization of novel Helicobacter pylori apo-fur-regulated target genes. J. Bacteriol. 195, 5526-5539. doi: 10.1128/ JB.01026-13

Carron, M. A., Tran, V. R., Sugawa, C., and Coticchia, J. M. (2006). Identification of Helicobacter pylori biofilms in human gastric mucosa. J. Gastrointest. Surg. 10, 712-717. doi: 10.1016/j.gassur.2005.10.019

Christensen-Dalsgaard, M., Jorgensen, M. G., and Gerdes, K. (2010). Three new RelE-homologous mRNA interferases of Escherichia coli differentially induced by environmental stresses. Mol. Microbiol. 75, 333-348. doi: 10.1111/j.13652958.2009.06969.x

Contreras, M., Thiberge, J. M., Mandrand-Berthelot, M. A., and Labigne, A. (2003). Characterization of the roles of NikR, a nickel-responsive pleiotropic autoregulator of Helicobacter pylori. Mol. Microbiol. 49, 947-963. doi: 10.1046/ j.1365-2958.2003.03621.x

Danielli, A., Amore, G., and Scarlato, V. (2010). Built shallow to maintain homeostasis and persistent infection: insight into the transcriptional regulatory network of the gastric human pathogen Helicobacter pylori. PLoS Pathog. 6:e1000938. doi: 10.1371/journal.ppat.1000938

Danielli, A., Roncarati, D., Delany, I., Chiarini, V., Rappuoli, R., and Scarlato, V. (2006). In vivo dissection of the Helicobacter pylori Fur regulatory circuit by genome-wide location analysis. J. Bacteriol. 188, 4654-4662. doi: 10.1128/jb. 00120-06 
Davis, G. S., Flannery, E. L., and Mobley, H. L. (2006). Helicobacter pylori HP1512 is a nickel-responsive NikR-regulated outer membrane protein. Infect. Immun. 74, 6811-6820. doi: 10.1128/iai.01188-06

Delany, I., Spohn, G., Pacheco, A. B., Ieva, R., Alaimo, C., Rappuoli, R., et al. (2002). Autoregulation of Helicobacter pylori Fur revealed by functional analysis of the iron-binding site. Mol. Microbiol. 46, 1107-1122. doi: 10.1046/j.1365-2958. 2002.03227.x

Delany, I., Spohn, G., Rappuoli, R., and Scarlato, V. (2001). The Fur repressor controls transcription of iron-activated and -repressed genes in Helicobacter pylori. Mol. Microbiol. 42, 1297-1309. doi: 10.1046/j.1365-2958.2001. 02696.x

Dietz, P., Gerlach, G., and Beier, D. (2002). Identification of target genes regulated by the two-component system HP166-HP165 of Helicobacter pylori. J. Bacteriol. 184, 350-362. doi: 10.1128/jb.184.2.350-362.2002

Donczew, R., Makowski, L., Jaworski, P., Bezulska, M., Nowaczyk, M., ZakrzewskaCzerwinska, J., et al. (2015). The atypical response regulator HP1021 controls formation of the Helicobacter pylori replication initiation complex. Mol. Microbiol. 95, 297-312. doi: 10.1111/mmi.12866

Ernst, F. D., Bereswill, S., Waidner, B., Stoof, J., Mader, U., Kusters, J. G., et al. (2005a). Transcriptional profiling of Helicobacter pylori Fur- and iron-regulated gene expression. Microbiology 151, 533-546. doi: 10.1099/mic.0.27404-0

Ernst, F. D., Kuipers, E. J., Heijens, A., Sarwari, R., Stoof, J., Penn, C. W., et al. (2005b). The nickel-responsive regulator NikR controls activation and repression of gene transcription in Helicobacter pylori. Infect. Immun. 73, 7252-7258. doi: 10.1128/IAI.73.11.7252-7258.2005

Foynes, S., Dorrell, N., Ward, S. J., Stabler, R. A., Mccolm, A. A., Rycroft, A. N., et al. (2000). Helicobacter pylori possesses two CheY response regulators and a histidine kinase sensor, CheA, which are essential for chemotaxis and colonization of the gastric mucosa. Infect. Immun. 68, 2016-2023. doi: 10.1128/ IAI.68.4.2016-2023.2000

Fujinaga, R., Nakazawa, T., and Shirai, M. (2001). Allelic exchange mutagenesis of rpoN encoding RNA-polymerase sigma54 subunit in Helicobacter pylori. J. Infect. Chemother. 7, 148-155. doi: 10.1007/s101560100027

Gaddy, J. A., Radin, J. N., Cullen, T. W., Chazin, W. J., Skaar, E. P., Trent, M. S., et al. (2015). Helicobacter pylori resists the antimicrobial activity of calprotectin via lipid A modification and associated biofilm formation. mBio 6:e1349-15. doi: 10.1128/mBio.01349-15

Gancz, H., Censini, S., and Merrell, D. S. (2006). Iron and pH homeostasis intersect at the level of Fur regulation in the gastric pathogen Helicobacter pylori. Infect. Immun. 74, 602-614. doi: 10.1128/IAI.74.1.602-614.2006

Haley, K. P., and Gaddy, J. A. (2015). Metalloregulation of Helicobacter pylori physiology and pathogenesis. Front. Microbiol. 6:911. doi: 10.3389/fmicb.2015. 00911

Harris, A. G., Hinds, F. E., Beckhouse, A. G., Kolesnikow, T., and Hazell, S. L. (2002). Resistance to hydrogen peroxide in Helicobacter pylori: role of catalase (KatA) and Fur, and functional analysis of a novel gene product designated 'KatA-associated protein', KapA (HP0874). Microbiology 148, 3813-3825. doi: 10.1099/00221287-148-12-3813

Hu, Y., Benedik, M. J., and Wood, T. K. (2012). Antitoxin DinJ influences the general stress response through transcript stabilizer CspE. Environ. Microbiol. 14, 669-679. doi: 10.1111/j.1462-2920.2011.02618.x

Hung, C. L., Cheng, H. H., Hsieh, W. C., Tsai, Z. T., Tsai, H. K., Chu, C. H., et al. (2015). The CrdRS two-component system in Helicobacter pylori responds to nitrosative stress. Mol. Microbiol. 97, 1128-1141. doi: 10.1111/mmi.13089

Jahn, C. E., Charkowski, A. O., and Willis, D. K. (2008). Evaluation of isolation methods and RNA integrity for bacterial RNA quantitation. J. Microbiol. Methods 75, 318-324. doi: 10.1016/j.mimet.2008.07.004

Josenhans, C., Niehus, E., Amersbach, S., Horster, A., Betz, C., Drescher, B., et al. (2002). Functional characterization of the antagonistic flagellar late regulators FliA and FlgM of Helicobacter pylori and their effects on the H. pylori transcriptome. Mol Microbiol 43, 307-322. doi: 10.1046/j.1365-2958. 2002.02765.x

Khan, S., Karim, A., and Iqbal, S. (2009). Helicobacter urease: niche construction at the single molecule level. J. Biosci. 34, 503-511. doi: 10.1007/s12038-0090069-4

Kim, N., Marcus, E. A., Wen, Y., Weeks, D. L., Scott, D. R., Jung, H. C., et al. (2004). Genes of Helicobacter pylori regulated by attachment to AGS cells. Infect. Immun. 72, 2358-2368. doi: 10.1128/IAI.72.4.2358-2368.2004
Li, T., Yin, N., Liu, H., Pei, J., and Lai, L. (2016). Novel inhibitors of toxin HipA reduce multidrug tolerant persisters. ACS Med. Chem. Lett. 7, 449-453. doi: 10.1021/acsmedchemlett.5b00420

Livak, K. J., and Schmittgen, T. D. (2001). Analysis of relative gene expression data using real-time quantitative PCR and the 2(-Delta Delta C(T)) Method. Methods 25, 402-408. doi: 10.1006/meth.2001.1262

Loh, J. T., Gupta, S. S., Friedman, D. B., Krezel, A. M., and Cover, T. L. (2010). Analysis of protein expression regulated by the Helicobacter pylori ArsRS two-component signal transduction system. J. Bacteriol. 192, 2034-2043. doi: 10.1128/JB.01703-08

Maisonneuve, E., Shakespeare, L. J., Jorgensen, M. G., and Gerdes, K. (2011). Bacterial persistence by RNA endonucleases. Proc. Natl. Acad. Sci. U.S.A. 108, 13206-13211. doi: 10.1073/pnas.1100186108

Marshall, B. J., and Warren, J. R. (1984). Unidentified curved bacilli in the stomach of patients with gastritis and peptic ulceration. Lancet 1, 1311-1315. doi: 10.1016/S0140-6736(84)91816-6

Martins, M. Q., Fortunato, A. S., Rodrigues, W. P., Partelli, F. L., Campostrini, E., Lidon, F. C., et al. (2017). Selection and validation of reference genes for accurate RT-qPCR data normalization in Coffea spp. under a climate changes context of interacting elevated [CO2] and temperature. Front. Plant Sci. 8:307. doi: $10.3389 /$ fpls.2017.00307

McGee, D. J., Langford, M. L., Watson, E. L., Carter, J. E., Chen, Y. T., and Ottemann, K. M. (2005). Colonization and inflammation deficiencies in Mongolian gerbils infected by Helicobacter pylori chemotaxis mutants. Infect. Immun. 73, 1820-1827. doi: 10.1128/iai.73.3.1820-1827.2005

Merrell, D. S., Goodrich, M. L., Otto, G., Tompkins, L. S., and Falkow, S. (2003a). $\mathrm{pH}$-regulated gene expression of the gastric pathogen Helicobacter pylori. Infect. Immun. 71, 3529-3539. doi: 10.1128/IAI.71.6.3529-3539.2003

Merrell, D. S., Thompson, L. J., Kim, C. C., Mitchell, H., Tompkins, L. S., Lee, A., et al. (2003b). Growth phase-dependent response of Helicobacter pylori to iron starvation. Infect. Immun. 71, 6510-6525. doi: 10.1128/IAI.71.11.6510-6525. 2003

Muller, C., Bahlawane, C., Aubert, S., Delay, C. M., Schauer, K., Michaud-Soret, I., et al. (2011). Hierarchical regulation of the NikR-mediated nickel response in Helicobacter pylori. Nucleic Acids Res. 39, 7564-7575. doi: 10.1093/nar/gkr460

Niehus, E., Gressmann, H., Ye, F., Schlapbach, R., Dehio, M., Dehio, C., et al. (2004). Genome-wide analysis of transcriptional hierarchy and feedback regulation in the flagellar system of Helicobacter pylori. Mol. Microbiol. 52, 947-961. doi: 10.1111/j.1365-2958.2004.04006.x

Ohnishi, N., Yuasa, H., Tanaka, S., Sawa, H., Miura, M., Matsui, A., et al. (2008). Transgenic expression of Helicobacter pylori CagA induces gastrointestinal and hematopoietic neoplasms in mouse. Proc. Natl. Acad. Sci. U.S.A. 105, 1003-1008. doi: 10.1073/pnas.0711183105

Olekhnovich, I. N., Vitko, S., Chertihin, O., Hontecillas, R., Viladomiu, M., Bassaganya-Riera, J., et al. (2013). Mutations to essential orphan response regulator HP1043 of Helicobacter pylori result in growth-stage regulatory defects. Infect. Immun. 81, 1439-1449. doi: 10.1128/IAI.01193-12

Olekhnovich, I. N., Vitko, S., Valliere, M., and Hoffman, P. S. (2014). Response to metronidazole and oxidative stress is mediated through homeostatic regulator HsrA (HP1043) in Helicobacter pylori. J. Bacteriol. 196, 729-739. doi: 10.1128/ JB.01047-13

Panthel, K., Dietz, P., Haas, R., and Beier, D. (2003). Two-component systems of Helicobacter pylori contribute to virulence in a mouse infection model. Infect. Immun. 71, 5381-5385. doi: 10.1128/iai.71.9.5381-5385.2003

Parsonnet, J., Friedman, G. D., Vandersteen, D. P., Chang, Y., Vogelman, J. H., Orentreich, N., et al. (1991). Helicobacter pylori infection and the risk of gastric carcinoma. N. Engl. J. Med. 325, 1127-1131. doi: 10.1056/ NEJM199110173251603

Pflock, M., Bathon, M., Schar, J., Muller, S., Mollenkopf, H., Meyer, T. F., et al. (2007a). The orphan response regulator HP1021 of Helicobacter pylori regulates transcription of a gene cluster presumably involved in acetone metabolism. J. Bacteriol. 189, 2339-2349. doi: 10.1128/JB.01827-06

Pflock, M., Finsterer, N., Joseph, B., Mollenkopf, H., Meyer, T. F., and Beier, D. (2006). Characterization of the ArsRS regulon of Helicobacter pylori, involved in acid adaptation. J. Bacteriol. 188, 3449-3462. doi: 10.1128/JB.188.10.34493462.2006

Pflock, M., Kennard, S., Delany, I., Scarlato, V., and Beier, D. (2005). Acidinduced activation of the urease promoters is mediated directly by the ArsRS 
two-component system of Helicobacter pylori. Infect. Immun. 73, 6437-6445. doi: 10.1128/IAI.73.10.6437-6445.2005

Pflock, M., Muller, S., and Beier, D. (2007b). The CrdRS (HP1365-HP1364) two-component system is not involved in ph-responsive gene regulation in the Helicobacter pylori strains 26695 and G27. Curr. Microbiol. 54, 320-324. doi: 10.1007/s00284-006-0520-9

Pich, O. Q., and Merrell, D. S. (2013). The ferric uptake regulator of Helicobacter pylori: a critical player in the battle for iron and colonization of the stomach. Future Microbiol. 8, 725-738. doi: 10.2217/fmb.13.43

Popescu, A., Karpay, A., Israel, D. A., Peek, R. M. Jr., and Krezel, A. M. (2005). Helicobacter pylori protein HP0222 belongs to Arc/MetJ family of transcriptional regulators. Proteins 59, 303-311. doi: 10.1002/prot.20406

Roncarati, D., Danielli, A., and Scarlato, V. (2014). The HrcA repressor is the thermosensor of the heat-shock regulatory circuit in the human pathogen Helicobacter pylori. Mol. Microbiol. 92, 910-920. doi: 10.1111/mmi.12600

Roncarati, D., Danielli, A., Spohn, G., Delany, I., and Scarlato, V. (2007). Transcriptional regulation of stress response and motility functions in Helicobacter pylori is mediated by HspR and HrcA. J. Bacteriol. 189, 7234-7243. doi: 10.1128/jb.00626-07

Schreiber, S., Konradt, M., Groll, C., Scheid, P., Hanauer, G., Werling, H. O., et al. (2004). The spatial orientation of Helicobacter pylori in the gastric mucus. Proc Natl. Acad. Sci. U.S.A. 101, 5024-5029. doi: 10.1073/pnas.0308386101

Servetas, S. L., Carpenter, B. M., Haley, K. P., Gilbreath, J. J., Gaddy, J. A., and Merrell, D. S. (2016). Characterization of key Helicobacter pylori regulators identifies a role for ArsRS in biofilm formation. J. Bacteriol. 198, 2536-2548. doi: 10.1128/JB.00324-16

Silva-Herzog, E., Mcdonald, E. M., Crooks, A. L., and Detweiler, C. S. (2015). Physiologic stresses reveal a Salmonella persister state and TA family toxins modulate tolerance to these stresses. PLOS ONE 10:e0141343. doi: 10.1371/ journal.pone. 0141343

Spohn, G., Danielli, A., Roncarati, D., Delany, I., Rappuoli, R., and Scarlato, V. (2004). Dual control of Helicobacter pylori heat shock gene transcription by HspR and HrcA. J. Bacteriol. 186, 2956-2965. doi: 10.1128/JB.186.10.29562965.2004

Spohn, G., Delany, I., Rappuoli, R., and Scarlato, V. (2002). Characterization of the HspR-mediated stress response in Helicobacter pylori. J. Bacteriol. 184, 2925-2930. doi: 10.1128/JB.184.11.2925-2930.2002

Spohn, G., and Scarlato, V. (1999a). The autoregulatory HspR repressor protein governs chaperone gene transcription in Helicobacter pylori. Mol. Microbiol. 34, 663-674. doi: 10.1046/j.1365-2958.1999.01625.x

Spohn, G., and Scarlato, V. (1999b). Motility of Helicobacter pylori is coordinately regulated by the transcriptional activator FlgR, an NtrC homolog. J. Bacteriol. 181, 593-599.

Sun, Y., Liu, S., Li, W., Shan, Y., Li, X., Lu, X., et al. (2013). Proteomic analysis of the function of sigma factor sigma54 in Helicobacter pylori survival with nutrition deficiency stress in vitro. PLoS ONE 8:e72920. doi: 10.1371/journal. pone.0072920

Terry, K., Williams, S. M., Connolly, L., and Ottemann, K. M. (2005). Chemotaxis plays multiple roles during Helicobacter pylori animal infection. Infect. Immun. 73, 803-811. doi: 10.1128/IAI.73.2.803-811.2005

Thompson, L. J., Merrell, D. S., Neilan, B. A., Mitchell, H., Lee, A., and Falkow, S. (2003). Gene expression profiling of Helicobacter pylori reveals a growth-phasedependent switch in virulence gene expression. Infect. Immun. 71, 2643-2655. doi: 10.1128/IAI.71.5.2643-2655.2003
Tomb, J. F., White, O., Kerlavage, A. R., Clayton, R. A., Sutton, G. G., Fleischmann, R. D., et al. (1997). The complete genome sequence of the gastric pathogen Helicobacter pylori. Nature 388, 539-547. doi: 10.1038/41483

Uemura, N., Okamoto, S., Yamamoto, S., Matsumura, N., Yamaguchi, S., Yamakido, M., et al. (2001). Helicobacter pylori infection and the development of gastric cancer. N. Engl. J. Med. 345, 784-789. doi: 10.1056/NEJMoa00 1999

van Vliet, A. H., Kuipers, E. J., Stoof, J., Poppelaars, S. W., and Kusters, J. G. (2004). Acid-responsive gene induction of ammonia-producing enzymes in Helicobacter pylori is mediated via a metal-responsive repressor cascade. Infect. Immun. 72, 766-773. doi: 10.1128/IAI.72.2.766-773.2004

van Vliet, A. H., Stoof, J., Poppelaars, S. W., Bereswill, S., Homuth, G., Kist, M., et al. (2003). Differential regulation of amidase- and formamidase-mediated ammonia production by the Helicobacter pylori fur repressor. J. Biol. Chem. 278, 9052-9057. doi: 10.1074/jbc.M207542200

Vannini, A., Roncarati, D., and Danielli, A. (2016). The cag-pathogenicity island encoded CncR1 sRNA oppositely modulates Helicobacter pylori motility and adhesion to host cells. Cell Mol. Life Sci. 73, 3151-3168. doi: 10.1007/s00018016-2151-Z

Vannini, A., Roncarati, D., Spinsanti, M., Scarlato, V., and Danielli, A. (2014). In depth analysis of the Helicobacter pylori cag pathogenicity island transcriptional responses. PLoS ONE 9:e98416. doi: 10.1371/journal.pone.0098416

Waidner, B., Melchers, K., Stahler, F. N., Kist, M., and Bereswill, S. (2005). The Helicobacter pylori CrdRS two-component regulation system (HP1364/HP1365) is required for copper-mediated induction of the copper resistance determinant CrdA. J. Bacteriol. 187, 4683-4688. doi: 10.1128/jb.187. 13.4683-4688.2005

Wang, G., Lo, L. F., and Maier, R. J. (2012). A histone-like protein of Helicobacter pylori protects DNA from stress damage and aids host colonization. DNA Repair 11, 733-740. doi: 10.1016/j.dnarep.2012.06.006

Wang, G., and Maier, R. J. (2015). A novel DNA-binding protein plays an important role in Helicobacter pylori stress tolerance and survival in the host. J. Bacteriol. 197, 973-982. doi: 10.1128/JB.02489- 14

Wang, X., and Wood, T. K. (2011). Toxin-antitoxin systems influence biofilm and persister cell formation and the general stress response. Appl. Environ. Microbiol. 77, 5577-5583. doi: 10.1128/AEM.05068-11

Wen, Y., Marcus, E. A., Matrubutham, U., Gleeson, M. A., Scott, D. R., and Sachs, G. (2003). Acid-adaptive genes of Helicobacter pylori. Infect. Immun. 71, 5921-5939. doi: 10.1128/iai.71.10.5921-5939.2003

Yamaguchi, Y., and Inouye, M. (2011). Regulation of growth and death in Escherichia coli by toxin-antitoxin systems. Nat. Rev. Microbiol. 9, 779-790. doi: $10.1038 /$ nrmicro2651

Conflict of Interest Statement: The authors declare that the research was conducted in the absence of any commercial or financial relationships that could be construed as a potential conflict of interest.

Copyright (C) 2017 De la Cruz, Ares, von Bargen, Panunzi, Martínez-Cruz, ValdezSalazar, Jiménez-Galicia and Torres. This is an open-access article distributed under the terms of the Creative Commons Attribution License (CC BY). The use, distribution or reproduction in other forums is permitted, provided the original author(s) or licensor are credited and that the original publication in this journal is cited, in accordance with accepted academic practice. No use, distribution or reproduction is permitted which does not comply with these terms. 